\title{
Metabolic Characteristics in Obese Patients Complicated by Mild Thyroid Hormone Deficiency
}

\author{
Authors

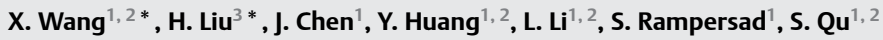 \\ Affiliations \\ Department of Endocrinology and Metabolism, Shanghai Tenth People's Hospital, Tongji University, Shanghai, China \\ Thyroid Institute of School of Medicine Tongji University, Shanghai, China \\ Department of Urology, Zhenjiang First People's Hospital, Zhenjiang, Jiangsu Province, China
}

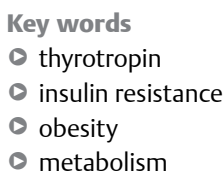

received 04.08 .2015 accepted 03.03.2016

\author{
Bibliography \\ Dol http://dx.doi.org/ \\ 10.1055/s-0042-105150 \\ Published online: \\ April 21, 2016 \\ Horm Metab Res 2016; \\ 48: 331-337 \\ (c) Georg Thieme Verlag KG \\ Stuttgart · New York \\ ISSN 0018-5043
}

\section{Correspondence}

\section{Professor S. Qu}

Department of Endocrinology and Metabolism

Shanghai $10^{\text {th }}$ People's Hospital Tongji University 301 Middle Yanchang Road Shanghai 200072 China

Tel.: + 86/21/66302531

Fax: + 86/21/66302 531

qushencn@hotmail.com

\section{Abstract \\ $\nabla$}

The prevalence of subclinical hypothyroidism (SH) is increasing, especially in obese people. The purpose of this study was to evaluate the difference in metabolic profiles between obese patients with mild increased thyrotropin (TSH) or with normal TSH. A total of 219 obese patients were recruited in this cross-sectional study. They were divided into 2 groups: obese patients with normal TSH (0.35-2.5 mU/l) and age-, and body mass index (BMI)-matched obese patients with higher-normal TSH $(2.5-5.5 \mathrm{mU} / \mathrm{l})$. We have named it compensatory hypothyroidism or mild thyroid hormone deficiency. Anthropometric data, glucose-lipid metabolism, markers of inflammation, body composition, and thyroid function parameters were measured. Results showed that: 1) The levels of fasting plasma glucose (FPG), high density lipoprotein cholesterol (HDL-C), and 25-hydroxyvitamin D levels were significantly lower in obese patients complicated by mild increased TSH than in obese patients with normal TSH $(\mathrm{p}<0.05)$. The fasting insulin (FINS) and $\mathrm{C}$ reactive protein (CRP) levels were significantly higher in obese patients compli-

\section{Introduction}

Subclinical hypothyroidism (SH) is a worldwide health problem and its prevalence is increasing all over the world especially in the patients with obesity and nonalcoholic fatty liver disease (NAFLD). SH is characterized by mildly increased thyroid stimulating hormone (TSH) (typically 5-10 mU/l) with normal free thyroxine (FT4) and free triodothyronine (FT3) levels. In most cases, increased TSH levels result from overt hypothyroidism [1]. Peripheral and central mechanism regulate $\mathrm{T} 3$ homeostasis together in human [2].

\footnotetext{
${ }^{*} \mathrm{X}$. Wang and $\mathrm{H}$. Liu contributed equally to this work
}

cated by mild increased TSH when compared to the obese patients with normal TSH $(\mathrm{p}<0.01)$. Jostel's TSH index (TSHI) and standard TSH index (sTSHI) were significantly higher in obesity with mild increased TSH when compared to obesity with normal TSH (both $\mathrm{p}<0.001$ ). Thyroid's secretory capacity (GT) was significantly lower in obesity with mild increased TSH when compared to obesity with normal TSH $(\mathrm{p}<0.001)$. 2) In the obese patients complicated by mild increased TSH group, serum TSH was significantly positively correlated with ALT, AST and CP $(\mathrm{p}<0.05)$. In the obese patients with normal TSH group, serum TSH was significantly positively correlated with UA ( $p<0.05)$. In all subjects, serum TSH was significantly positively correlated with ALT, AST, FINS, CP, CRP, and UA ( $\mathrm{p}<0.05)$, but negatively with DBP, FPG, and HDL-C ( $p<0.05)$. 3) There was significant difference of the prevalence of hyperinsulinemia and impaired fasting glucose (IFG) between the 2 groups $(\mathrm{p}<0.05)$. In Conclusion, obesity complicated by mild increased TSH manifested higher fasting insulin levels, more severe chronic low-grade inflammation, and lower HDL-C levels than obesity with normal TSH.

Cut-off of circulating TSH value above $2.5 \mathrm{mIU} / \mathrm{l}$ has also been proposed for defining $\mathrm{SH}[3,4]$. There is a positive association between body mass index and increased TSH levels [5]. However, the causal relationship between obesity and SH is not fully understood [6].

Previous studies have shown that $\mathrm{SH}$ has negative metabolic effects on the affected patients [7]. $\mathrm{SH}$ is related to a variety of metabolic abnormalities such as increased body mass index and abnormal lipoprotein profiles [8]. Each unit increase in TSH was associated with a $3 \%$ increase in the odds of prevalent metabolic syndrome [9]. Additionally, cardiac structural and functional deteriorations are associated with $\mathrm{SH}$ in obese 
patients [10]. Clinical and the subclinical manifest forms of thyroid dysfunctions are associated with an increased risk to develop atrial fibrillation and obesity $(R R=2.21)$ is one of the main risk factors that led to atrial fibrillation among the patients with $\mathrm{SH}$ [11]. A previous study found that $\mathrm{SH}$ is a secondary phenomenon to the abnormal fat accumulation and redistributions and not a real hypothyroid state in morbidly obese subjects, as $\mathrm{SH}$ is usually corrected after laparoscopic sleeve gastrectomy in the morbidly obese patients [12]. Previous studies also have shown that dyslipidemia in the high-normal TSH group was more serious than the lower-normal TSH group [13].

However, it remains unknown to find out the difference of metabolic characteristics in obese patients with normal TSH and mild increased TSH, which we have named as mild thyroid hormone deficiency or compensatory hypothyroidism. In the present study, 219 obese patients were enrolled to investigate the different patterns of metabolic profiles with normal TSH and mild increased TSH.

\section{Materials and Methods}

$\nabla$

Subjects

This cross-sectional study enrolled 219 obese Chinese patients from the outpatient department of Shanghai Tenth People's Hospital aged between 18-60 years old with body mass index (BMI) over $28 \mathrm{~kg} / \mathrm{m}^{2}$. All the subjects signed the informed consent. The patients were divided into 2 groups: 101 obese patients with normal TSH and 118 patients with mild increased TSH, which we have named as compensatory hypothyroidism or mild thyroid hormone deficiency. Both groups were matched for age and BMI. Patients with normal TSH were defined in this study as a TSH level ranging from 0.35 to $2.5 \mathrm{mU} / \mathrm{l}$ and a normal free-thyroxine level. Mild increased TSH was defined in this study as a TSH level ranging from 2.5 to $5.5 \mathrm{mU} / \mathrm{l}$ with a normal free-thyroxine level $[3,4]$. This study and research protocols were approved by the ethics committee of Shanghai Tenth People's Hospital. The exclusion criteria were as follows: 1) Patients having a history of thyroid disease under thyroxine or antithyroid drugs treatment; 2) Patients taking medications affecting thyroid function; and 3) Patients with overt hyperthyroidism or overt hypothyroidism.

\section{Anthropometric measurement}

Weight, BMI, percentage of body fat (\%), visceral fat fraction, and basal metabolism (BM) were measured by Omron HBF-358 (Q40102010L01322F, Japan) with the subjects wearing light clothes and without shoes. Waist circumstances (WC) was measured at the midway between the lower rib margin and the iliac crest with the subjects standing with their feet $25-30 \mathrm{~cm}$ apart, and without undue pressure applied to the measuring tape. Neck circumference (NC) was measured with head upright and eyes facing forward, horizontally at the upper margin of laryngeal prominence. Hip circumstance (HC) was measured at the fullest point around the buttocks by a specialized personnel. Waist/hip ratio was calculated with the following formula: Waist/hip ratio $=$ waistline $(\mathrm{cm}) /$ hipline $(\mathrm{cm})$. Blood pressure was measured by a mercury-gravity sphygmomanometer after the patients have rested for $10 \mathrm{~min}$ in a sitting position. All the anthropometric data were measured twice and their average value was adopted for analysis.

\section{Laboratory measurementws}

Blood samples were obtained after overnight fasting of 8-10h for the measurements of FT3, FT4, total thyroxine (TT3), total triiodothyronine (TT4), TSH, alanine transaminase (ALT), aspartate aminotransferase (AST), fasting plasma glucose(FPG), fasting insulin (FINS), fasting $C$ peptide (CP), hemoglobin A1C (HbA1c), total cholesterol (TC), triglyceride (TG), high density lipoprotein cholesterol (HDL-C), low density lipoprotein cholesterol (LDL-C), C reactive protein (CRP), free fatty acids (FFA), uric acid (UA), and 25-hydroxyvitamin D. The Homoeostasis Model of Insulin Resistance (HOMA-IR) score was calculated to estimate the level of insulin resistance using the following formula: HOMA-IR = FPG $(\mathrm{mol} / \mathrm{l}) \times$ FINS $(\mu \mathrm{U} / \mathrm{ml}) / 22.5$. Static parameter for the function of pituitary was evaluated by Jostel's TSH index (TSHI) with an accurate estimate of the severity of pituitary dysfunction with the following formula: TSHI $=\log \mathrm{TSH}+0.1345 \times$ FT4 [14]. Standard TSH index (sTSHI) also was calculated to assess the pituitary thyrotroph function. It was defined as STSHI = (TSH2.70)/0.676 [14]. The function of thyroid secretory was evaluated as thyroid's secretory capacity (GT), which was calculated as GT $=\left[\beta_{\mathrm{T}} \times\left(\mathrm{D}_{\mathrm{T}}+\mathrm{TSH}\right) \times \mathrm{TT} 4\right] / \alpha_{\mathrm{T}} \times \mathrm{TSH}$ [15]. The function of deiodination was evaluated by deiodinase sum activity (GD), which was calculated as $\mathrm{GD}=\left[\beta_{31} \times\left(\mathrm{K}_{\mathrm{M} 1}+\mathrm{FT} 4\right) \times \mathrm{TT} 3\right] / \alpha_{31} \times \mathrm{FT} 4[15]$. Constants in these formulas were as following: $\beta_{\mathrm{T}}=1.1 \times 10^{-6} / \mathrm{s}$, $\mathrm{D}_{\mathrm{T}}=2.75 \mathrm{mU} / \mathrm{l}, \alpha_{\mathrm{T}}=0.1 / \mathrm{l}, \beta_{31}=8 \times 10^{-6} / \mathrm{s}, \mathrm{K}_{\mathrm{M} 1}=\mathrm{K}_{\mathrm{M} 1} 5 \times 10^{-7} \mathrm{~mol} / \mathrm{l}$, and $\alpha_{31}=0.026 / 1$ [15].

\section{Body fat content and distribution measurements}

Body fat content and its composition were measured using dual X-ray absorptiometry (DEXA) (Hologic QDR4500, USA). DEXA data included fat mass in different areas (limbs, trunk, trunk, head and total fat mass, total lean mass, total fat mass \%, and trunk/limbs ratio).

\section{Definition of dyslipidemia, impaired fasting glucose} tolerance, hyperinsulinemia and hyperuricemia High TG was defined as fasting plasma TG $\geq 1.7 \mathrm{mmol} / \mathrm{l}$, low HDL-C was defined as fasting $\mathrm{HDL}-\mathrm{C}<1.04 \mathrm{mmol} / \mathrm{l}$, high $\mathrm{LDL}-\mathrm{C}$ was defined as $\mathrm{LDL}-\mathrm{C} \geq 3.37 \mathrm{mmol} / \mathrm{l}$, and high TC was defined as $\mathrm{TCH} \geq 5.18 \mathrm{mmol} / \mathrm{l}[16]$. Impaired fasting glucose (IFG) was defined as fasting plasma glucose level ranging from $6.1 \mathrm{mmol} / \mathrm{l}$ to $6.9 \mathrm{mmol} / \mathrm{l}$ [17]. Hyperinsulinemia was defined as fasting plasma insulin concentrations $\geq 15 \mathrm{mU} / 1$ [18]. Hyperuricemia was defined as serum uric acid concentration $\geq 7 \mathrm{mg} / \mathrm{dl}(\geq 417 \mu \mathrm{mol} / \mathrm{l})$ and $\geq 6 \mathrm{mg} / \mathrm{dl}(\geq 357 \mu \mathrm{mol} / \mathrm{l}$ ) in men and women, respectively [19].

\section{Statistical analysis}

Statistical analysis was performed using SPSS 17.0 software. All continuous data were expressed as means \pm standard deviation (SD). The comparison between the 2 groups was analyzed by independent-samples $t$-test. The correlation between serum TSH and metabolic variables was assessed using Pearson's correlation analysis. Comparison of the count data was performed by $\mathrm{X}^{2}$ test. A value of $\mathrm{p}<0.05$ was considered statistically significant.

\section{Results}

$\nabla$

Anthropometric measurements and glucose metabolism between the 2 groups

The baseline characteristics of the patients are shown in $\bullet$ Table 1. Age and BMI well matched obese patients complicated by 
Table 1 Comparison of metabolic profiles of the patients.

\begin{tabular}{|c|c|c|c|}
\hline & $\begin{array}{l}\text { Obesity+normal } \\
\text { TSH }\end{array}$ & $\begin{array}{l}\text { Obesity + mild } \\
\text { increased TSH }\end{array}$ & p-Value \\
\hline Number & 101 & 118 & \\
\hline$M / F$ & $40 / 61$ & $33 / 85$ & 0.069 \\
\hline Age (years) & $28.56 \pm 7.54$ & $26.50 \pm 9.27$ & 0.104 \\
\hline Weight (kg) & $90.57 \pm 19.23$ & $91.73 \pm 19.55$ & 0.663 \\
\hline BMI $\left(\mathrm{kg} / \mathrm{m}^{2}\right)$ & $33.29 \pm 10.89$ & $33.26 \pm 5.59$ & 0.979 \\
\hline $\mathrm{NC}(\mathrm{cm})$ & $39.52 \pm 4.62$ & $39.12 \pm 4.71$ & 0.585 \\
\hline WC $(\mathrm{cm})$ & $102.38 \pm 14.40$ & $104.99 \pm 13.76$ & 0.218 \\
\hline $\mathrm{HC}(\mathrm{cm})$ & $109.41 \pm 9.98$ & $111.56 \pm 11.05$ & 0.177 \\
\hline Waist/hip ratio & $0.93 \pm 0.08$ & $0.94 \pm 0.06$ & 0.564 \\
\hline $\begin{array}{l}\text { Percentage of body } \\
\text { fat }(\%)\end{array}$ & $34.72 \pm 4.87$ & $35.00 \pm 4.86$ & 0.695 \\
\hline Visceral fat fraction & $14.44 \pm 6.37$ & $14.15 \pm 6.74$ & 0.772 \\
\hline BM (kcal) & $1725.46 \pm 296.76$ & $1753.36 \pm 315.81$ & 0.538 \\
\hline $\mathrm{SBP}(\mathrm{mmHg})$ & $134.14 \pm 19.62$ & $129.29 \pm 17.26$ & 0.154 \\
\hline $\mathrm{DBP}(\mathrm{mmHg})$ & $85.27 \pm 11.40$ & $82.07 \pm 13.29$ & 0.166 \\
\hline FT3 (pmol/l) & $4.72 \pm 0.67$ & $4.90 \pm 0.68$ & 0.060 \\
\hline FT4 (pmol/l) & $15.72 \pm 2.24$ & $15.71 \pm 2.30$ & 0.977 \\
\hline TT3 (nmol/l) & $1.77 \pm 0.49$ & $1.94 \pm 0.63$ & 0.224 \\
\hline TT4 (nmol/l) & $114.42 \pm 23.38$ & $111.88 \pm 29.29$ & 0.702 \\
\hline $\mathrm{TSH}(\mathrm{mU} / \mathrm{l})$ & $1.42 \pm 0.51$ & $3.64 \pm 1.43$ & $<0.001^{* *}$ \\
\hline TSHI & $2.21 \pm 0.43$ & $2.65 \pm 0.32$ & $<0.001^{* *}$ \\
\hline sTSHI & $-1.72 \pm 0.61$ & $1.30 \pm 0.97$ & $<0.001^{* *}$ \\
\hline GT (pmol/s) & $3.40 \pm 0.80$ & $2.24 \pm 0.65$ & $<0.001^{* *}$ \\
\hline $\mathrm{GD}(\mathrm{nmol} / \mathrm{s})$ & $18.04 \pm 4.96$ & $18.97 \pm 6.03$ & 0.539 \\
\hline $\operatorname{ALT}(\mathrm{U} / \mathrm{I})$ & $43.04 \pm 28.38$ & $48.83 \pm 39.72$ & 0.266 \\
\hline AST (U/I) & $30.77 \pm 16.95$ & $33.85 \pm 22.29$ & 0.318 \\
\hline FPG $(\mathrm{mmol} / \mathrm{l})$ & $6.17 \pm 2.39$ & $5.53 \pm 2.01$ & $0.044^{*}$ \\
\hline FINS $(\mu \mathrm{U} / \mathrm{I})$ & $22.93 \pm 12.93$ & $29.35 \pm 16.61$ & $0.003^{* *}$ \\
\hline C-peptide(ng/ml) & $3.77 \pm 1.50$ & $3.99 \pm 1.49$ & 0.330 \\
\hline HOMA-IR & $6.38 \pm 4.35$ & $7.28 \pm 6.02$ & 0.241 \\
\hline $\mathrm{HbA} 1 \mathrm{c}(\mathrm{mmol} / \mathrm{mol})$ & $53.98 \pm 25.94$ & $46.59 \pm 19.06$ & 0.198 \\
\hline $\mathrm{TC}(\mathrm{mmol} / \mathrm{l})$ & $5.03 \pm 1.71$ & $4.79 \pm 1.09$ & 0.256 \\
\hline TG (mmol/l) & $2.16 \pm 1.96$ & $2.00 \pm 1.22$ & 0.494 \\
\hline HDL-C (mmol/l) & $1.16 \pm 0.29$ & $1.07 \pm 0.19$ & $0.024^{*}$ \\
\hline LDL-C (mmol/l) & $2.83 \pm 0.88$ & $2.92 \pm 0.70$ & 0.455 \\
\hline CRP (mg/l) & $3.19 \pm 2.41$ & $4.26 \pm 2.50$ & $0.008^{* *}$ \\
\hline $\mathrm{FFA}(\mathrm{mmol} / \mathrm{l})$ & $0.60 \pm 0.23$ & $0.63 \pm 0.21$ & 0.293 \\
\hline $\mathrm{UA}(\mu \mathrm{mol} / \mathrm{l})$ & $392.05 \pm 109.21$ & $416.43 \pm 110.85$ & 0.155 \\
\hline $\begin{array}{l}\text { 25-Hydroxyvitamin D } \\
(\mathrm{nmol} / \mathrm{l})\end{array}$ & $52.58 \pm 8.92$ & $42.00 \pm 12.99$ & $0.012^{*}$ \\
\hline
\end{tabular}

increased TSH or normal TST were included. The levels of FINS were significantly higher in the obesity with mild increased TSH group than in the obesity with normal TSH group $(29.35 \pm 16.61$ vs. $22.93 \pm 12.93 \mu \mathrm{U} / \mathrm{l}, \mathrm{p}=0.003$ ). The levels of FPG were significantly lower in the obesity with mild increased TSH group when compared to the obesity with normal TSH group $(5.53 \pm 2.01$ vs. $6.17 \pm 2.39 \mathrm{mmol} / \mathrm{l}, \mathrm{p}=0.044$ ). However, there was no significant difference in NC, WC, HC, waist/hip ratio, percentage of body fat, visceral fat fraction, BM, diastolic blood pressure (DBP), systolic pressure (SBP), CP, HOMA-IR, and HbA1c ( $p>0.05$ ). The WC, HC, waist/hip ratio, percentage of body fat, $\mathrm{CP}$, and HOMA-IR were slightly higher in the obesity with mild increased TSH group without significant difference ( $p>0.05$ ). Additionally, SBP, DBP, and $\mathrm{HbA1} \mathrm{c}$ were slightly lower in the obesity with mild increased TSH group also without significant difference $(p>0.05)$.
Table 2 Fat content and fat distribution of the patients.

\begin{tabular}{|c|c|c|c|}
\hline & Obesity+normal TSH & $\begin{array}{l}\text { Obesity + mild } \\
\text { increased TSH }\end{array}$ & $\begin{array}{l}\text { p- } \\
\text { Value }\end{array}$ \\
\hline $\begin{array}{l}\text { Upperlimb fat } \\
\text { mass }(\mathrm{g})\end{array}$ & $5209.54 \pm 1492.79$ & $5621.64 \pm 1471.14$ & 0.198 \\
\hline $\begin{array}{l}\text { Lower limb fat } \\
\text { mass }(\mathrm{g})\end{array}$ & $9864.86 \pm 2504.47$ & $10073.48 \pm 2798.38$ & 0.716 \\
\hline Limb fat mass $(\mathrm{g})$ & $15074.40 \pm 3463.37$ & $15680.16 \pm 3961.03$ & 0.452 \\
\hline Trunk fat mass (g) & $17419.82 \pm 4321.45$ & $17373.72 \pm 4580.25$ & 0.962 \\
\hline Trunk fat mass (\%) & $40.72 \pm 4.99$ & $41.16 \pm 5.75$ & 0.705 \\
\hline Head fat mass (g) & $1659.68 \pm 367.30$ & $1680.13 \pm 321.33$ & 0.786 \\
\hline Total fat mass (g) & $34148.55 \pm 7323.08$ & $34924.53 \pm 7286.29$ & 0.626 \\
\hline Tota fat mass (\%) & $38.84 \pm 5.47$ & $39.38 \pm 5.11$ & 0.642 \\
\hline Total lean mass $(\mathrm{g})$ & $50799.66 \pm 11780.50$ & $51710.93 \pm 10636.37$ & 0.727 \\
\hline $\begin{array}{l}\text { Trunk/limb fat } \\
\text { mass }\end{array}$ & $1.17 \pm 0.26$ & $1.13 \pm 0.30$ & 0.474 \\
\hline
\end{tabular}

\section{Lipid profiles, inflammation, and liver function} between the 2 groups

The data of lipid profile, inflammation, and liver function in these subjects are presented in $\odot$ Table 1 . Data on liver function showed that there was no significant difference in ALT and AST between the 2 groups ( $p>0.05$ ). However, levels of HDL-C were significantly lower in obesity with mild increased TSH group when compared to the obesity with normal TSH $(1.07 \pm 0.19$ vs. $1.16 \pm 0.29 \mathrm{mmol} / \mathrm{l}, \mathrm{p}=0.024)$. The lipid profiles of TC, TG, and LDL-C showed no significant difference between the 2 groups ( $p>0.05$ ). Additionally, the levels of CRP were significantly higher in the obesity with mild increased TSH group than in the obesity with normal TSH group $(4.26 \pm 2.50$ vs. $3.19 \pm 2.41 \mathrm{mg} / \mathrm{l}$, $\mathrm{p}=0.008$ ). The concentrations of inflammation markers UA and FFA did not differ between both groups ( $p>0.05)$. Additionally, the levels of 25-hydroxyvitamin D were lower in the obesity with mild increased TSH group than obesity with normal TSH group with statistical difference $(42.00 \pm 12.99$ vs. $52.58 \pm 8.92 \mathrm{nmol} / \mathrm{l}, \mathrm{p}=0.012$ ). Results of static parameters for the function of pituitary, thyroid, and deiodinases showed that TSHI and STSHI were significantly higher in obesity with mild increased TSH when compared to obesity with normal TSH (both $\mathrm{p}<0.001$ ). GT was significantly lower in obesity with mild increased TSH group when compared to obesity with normal TSH group $(p<0.001)$. Additionally, GD did not differ between both groups $(p>0.05)$.

\section{Fat distribution}

The fat content and its distribution did not differ between both groups ( $p>0.05$ ). All these data are shown in $\odot$ Table 2.

\section{Correlation of serum TSH with anthropometric and metabolic variables}

In obese patients complicated by mild increased TSH group, serum TSH was significantly positively associated with ALT, AST, and $\mathrm{CP}(\mathrm{p}<0.05)$. In obese patients with normal TSH, serum TSH was significantly positively correlated with UA $(p<0.05)$. In all subjects, serum TSH was significantly positively correlated with ALT, AST, FINS, CP, CRP, and UA ( $p<0.05)$, but significantly negatively correlated with DBP, FPG and HDL-C $(\mathrm{p}<0.05)$. All the correlation of serum TSH with anthropogical and metabolic variables are presented in $\bullet$ Table 3 . 


\begin{tabular}{|c|c|c|c|c|c|c|}
\hline \multirow[t]{2}{*}{ Parameters } & \multicolumn{2}{|c|}{ Obesity+normal TSH } & \multicolumn{2}{|c|}{ Obesity + mild increased TSH } & \multicolumn{2}{|l|}{ Total } \\
\hline & $\mathbf{r}$ & $\mathbf{p}$ & $\mathbf{r}$ & $\mathbf{p}$ & $\mathbf{r}$ & $\mathbf{p}$ \\
\hline BMI & 0.039 & 0.709 & 0.093 & 0.327 & 0.039 & 0.571 \\
\hline NC & 0.058 & 0.621 & 0.094 & 0.375 & 0.026 & 0.744 \\
\hline WC & -0.107 & 0.345 & 0.136 & 0.177 & 0.117 & 0.119 \\
\hline $\mathrm{HC}$ & -0.042 & 0.711 & 0.074 & 0.462 & 0.105 & 0.162 \\
\hline Waist/hip ratio & -0.128 & 0.259 & 0.125 & 0.216 & 0.069 & 0.360 \\
\hline SBP & 0.092 & 0.509 & 0.026 & 0.835 & -0.068 & 0.464 \\
\hline DBP & 0.012 & 0.930 & -0.201 & 0.109 & -0.192 & $0.036^{*}$ \\
\hline ALT & -0.040 & 0.723 & 0.320 & $0.002^{* *}$ & 0.232 & $0.002^{* *}$ \\
\hline AST & -0.028 & 0.813 & 0.380 & $<0.001^{* *}$ & 0.267 & $0.001^{* *}$ \\
\hline FPG & -0.057 & 0.596 & -0.071 & 0.452 & -0.142 & $0.043^{*}$ \\
\hline FINS & -0.086 & 0.415 & 0.184 & 0.052 & 0.240 & $0.001^{*}$ \\
\hline C-peptide & 0.006 & 0.955 & 0.227 & $0.028^{*}$ & 0.171 & $0.024^{*}$ \\
\hline HOMA-IR & -0.152 & 0.158 & 0.144 & 0.135 & 0.126 & 0.078 \\
\hline $\mathrm{HbA1c}$ & 0.017 & 0.936 & 0.059 & 0.723 & -0.086 & 0.503 \\
\hline TC & 0.077 & 0.487 & 0.016 & 0.876 & -0.043 & 0.561 \\
\hline TG & 0.133 & 0.221 & 0.015 & 0.882 & -0.006 & 0.933 \\
\hline $\mathrm{HDL}-\mathrm{C}$ & -0.107 & 0.335 & -0.013 & 0.901 & -0.151 & $0.045^{*}$ \\
\hline LDL-C & -0.015 & 0.893 & -0.058 & 0.590 & 0.009 & 0.910 \\
\hline CRP & -0.070 & 0.575 & 0.128 & 0.235 & 0.204 & $0.011^{*}$ \\
\hline FFA & -0.089 & 0.421 & -0.022 & 0.831 & 0.032 & 0.664 \\
\hline UA & 0.240 & $0.041^{*}$ & 0.196 & 0.055 & 0.210 & $0.006^{* *}$ \\
\hline 25-Hydroxyvitamin D & -0.221 & 0.489 & 0.247 & 0.308 & -0.122 & 0.513 \\
\hline Upperlimb fat mass & -0.241 & 0.115 & -0.032 & 0.840 & 0.045 & 0.682 \\
\hline Lower limb fat mass & -0.026 & 0.869 & 0.167 & 0.289 & 0.102 & 0.352 \\
\hline Limb fat mass & -0.123 & 0.428 & 0.110 & 0.487 & 0.091 & 0.406 \\
\hline Trunk fat mass & -0.135 & 0.381 & 0.022 & 0.891 & -0.018 & 0.868 \\
\hline Trunk fat mass \% & -0.225 & 0.148 & -0.050 & 0.750 & -0.031 & 0.774 \\
\hline Head fat mass & -0.108 & 0.489 & 0.101 & 0.525 & 0.042 & 0.703 \\
\hline Total fat mass & -0.145 & 0.355 & 0.152 & 0.335 & 0.079 & 0.470 \\
\hline Tota fat mass \% & -0.145 & 0.359 & -0.063 & 0.689 & -0.016 & 0.886 \\
\hline Total lean mass & -0.031 & 0.854 & 0.105 & 0.541 & 0.066 & 0.571 \\
\hline Trunk/limb fat mass & 0.018 & 0.905 & -0.117 & 0.462 & -0.108 & 0.322 \\
\hline
\end{tabular}

Table 3 Correlations of serum TSH levels with anthropometric variables, glucose-lipid metabolism, and fat distribution.

compared with obesity+ normal TSH group, ${ }^{*} p<0.05,{ }^{*}{ }^{*} p<0.01$

Table 4 The clinical and biochemical features of the obese patients with lower and higher TSH.

\begin{tabular}{|lllllllc} 
& High-TC (\%) & High-TG (\%) & Low-HDL (\%) & High-LDL (\%) & Hyperuricemia (\%) & Hyperinsulinemia (\%) & IFG (\%) \\
\hline Obesity+ normal TSH & 48.5 & 55.4 & 31.7 & 43.6 & 73.3 & 73 & 42.6 \\
\hline Obesity+mild increased TSH & 44.5 & 58 & 36.1 & 47.1 & 75.6 & 84 & 27.7 \\
\hline p-Value & 0.556 & 0.705 & 0.488 & 0.604 & 0.688 & $0.046^{*}$ & $0.021^{*}$
\end{tabular}

Data are presented as n (\%); compared with obesity + normal TSH group, ${ }^{*} \mathrm{p}<0.05$

\section{The biochemical features}

The prevalence of hyperinsulinemia was significantly higher in mild increased TSH group when compared to the normal TSH group $(\mathrm{p}=0.046)$. However, the prevalence of high-TC, high-TG low-HDL, high-LDL, and hyperuricemia have no significant difference between the 2 groups ( $p>0.05$ ). There were slightly higher prevalence of high-TG, low-HDL, and high-LDL in mild increased TSH group than the normal TSH group but without significant difference $(p>0.05)$. All these data are presented in $\odot$ Table 4.

\section{Discussion and Conclusions \\ $\nabla$}

$\mathrm{SH}$ is defined as an elevated TSH associated with normal levels of free thyroxine. The most common endogenous cause of $\mathrm{SH}$ is chronic autoimmune thyroiditis associated with antithyroid peroxidase antibodies [20]. The prevalence of SH is significantly higher in obese patients than in general population [21]. Current evidence shows that substantial weight loss results in a decreased TSH levels, which suggests a causal relationship between obesity and SH is not anticipated [22]. Demidova et al. [23] reported that abnormally high level of TSH may be a component of metabolic syndrome (MS) in 60 women with obesity and hypothyroidism. Serum TSH in MS group was higher as compared to the non-MS group $(\mathrm{p}<0.05)$ [24]. The prevalence of SH is also influenced by risk factors like type 2 diabetes (T2DM) [25]. Patients with hypothyroid dysfunction possess several cardiometabolic risk factors that include obesity. High TSH level in subclinical hypothyroidism is a risk factor in atherosclerosis formation [26]. The relatively low thyroid hormone level in obese patients may result in increased TSH levels. The association between TSH and BMI is related to leptin concentration in obesity is related to BMI and TSH, indicating the increased TSH in the obesity is the result of fat mass accumulation and a positive energy-balance [27]. TSH levels within the reference range was positively associated with BMI $(\mathrm{p}<0.001)$ and with the prevalence of obesity $(p<0.005)[28]$. Overweight also increases risk 
of thyroid dysfunction in iodine-deficient pregnant women [29]. Additionally, the compensatory hypothyroidism with highernormal TSH that has not yet reached SH diagnostic levels, also showed more severe dyslipidemia than the lower-normal TSH group [13]. In this study, we compared the metabolic profiles of the obese patients with mild increased TSH (above $2.5 \mathrm{mIU} / \mathrm{l}$ ), also defined as SH $[3,4]$ to the obese patients with normal TSH. Results showed significant difference in glucose-lipid metabolism and inflammation state.

In another study, patients with SH had a significantly higher BMI than the controls $(p<0.001)[30]$. Previous studies showed that TSH levels were significantly higher in obese patients and were positively correlated with BMI and waistline [10,31,32]. However, bariatric surgery can improve or normalize thyroid hormone levels as a mean BMI reduction from 49 to $32 \mathrm{~kg} / \mathrm{m}^{2}$ was associated with a reduction in the TSH levels from 4.5 to $1.9 \mathrm{mU} /$ $\mathrm{ml}$ [32]. There is also a significant correlation between a TSH decrease and weight loss in the morbidly obese patients 12 months after bariatric surgery $(p=0.007)$ [12]. Central obesity is associated with clinical and subclinical hypothyroidism, independent of age, sex, BMI, and type2 diabetes [33]. However, central obesity parameters of WC, waist/hip ratio, and trunk fat mass \% were slightly higher in obese patients with mild increased TSH. No statistical difference was noted in this study. Liu et al. [34] explored the relationship between different levels of TSH and blood pressure in patients with $\mathrm{SH}$ with result showing that the hypertension in SH group was significantly higher than in the euthyroid group. In this study, we compared the blood pressure between patients of the 2 groups with results showing a slightly lower blood pressure in the obesity with mild thyroid hormone deficiency. Additionally, the serum TSH levels were significantly negatively correlated with DBP in all subjects in this study.

Previous study showed that elevated TSH values in obese adolescents with nonalcoholic fatty liver disease (NAFLD) were positively correlated with insulin $(r=0.607, p=0.001)$ and HOMA-IR $(r=0.596, p=0.002)$ [35]. TSH decrease has a significant correlation with glucose and glycated hemoglobin decrease at 6 months after bariatric surgery in the morbidly obese patients [12]. Our study investigated glucose metabolism in the obesity with mild increased TSH and normal TSH groups and the results indicated that fasting insulin levels were significantly higher in the obesity with mild thyroid hormone deficiency and serum TSH was significantly positively correlated with FINS, which may elaborate the obesity and increased TSH levels together leading to the hyperinsulinemia and slightly insulin resistance.

$\mathrm{SH}$ is a relatively common endocrine disorder accompanied with lipid abnormalities and is also one of the causes of secondary lipid abnormalities $[7,36]$. Serum TC and TG levels were significantly higher in women with $\mathrm{SH}$ and for a while $\mathrm{SH}$ patients have lower levels of HDL-C as compared to euthyroid controls [7]. Additionally, TG levels is significantly higher and HDL-C is lower in $\mathrm{SH}$ group when compared with euthyroid controls $(p<0.05)$ [24]. Elevated TSH values in obese adolescents with NAFLD were positively correlated with TC $(r=0.606, p=0.001)$, TG $(r=0.476, p=0.016)$ and LDL-C $(r=0.461, p=0.004)$ [35]. TSH has positive correlations with serum TC, TG and LDL-C levels regardless of sex, age, season, obesity, or menopausal status (all $\mathrm{p}<0.01$ ) [37]. There is a significant association between TSH decrease and TG and HDL-C reductions after bariatric surgery in morbidly obese patients [12]. Another study showed that the TC, TG and HDL-C levels between SH and euthyroid subjects were not different [38]. However, the influence of a raised serum TSH on the lipid metabolism in morbid-obese, compared to nonobese patients, is different [39]. It has been reported that morbid-obese patients with increased serum TSH show lower serum TC levels $(200.8 \pm 35.6$ vs. $226.9 \pm 41.4 \mathrm{mg} / \mathrm{dl}, \mathrm{p}<0.001)$ and a lower prevalence of hypercholesterolemia (50.9 vs. $72.7 \%$, $\mathrm{p}<0.01$ ) than the nonobese patients [39]. In this study, the HDL-C levels were significantly lower in the obesity with mild increased TSH group than the obesity with normal TSH group. Moreover, serum TSH correlated negatively with the levels of HDL-C in all subjects. Therefore, correction of dyslipidemia by levothyroxine supplement in the obesity with mild increased TSH may be effective. Further study is needed to verify the difference of lipid profiles between obesity with normal TSH and the obese patients with mild thyroid hormone deficiency and the therapeutic effect of levothyroxine in improving dyslipidemia in the obesity.

The adipocytes and pre-adipocytes express TSH receptors, responsible for the action of TSH in fat tissue [40]. Stimulation of brown adipose tissue through thyroid-hormone-mediated pathways has been proven in previous study to be a promising therapeutic method for obesity [41]. The underlying mechanism of the relationship between TSH and obesity is that TSH acted as a master regulator of adipogenesis indicating that modification of the AMPK/PPARY/GPAT3 (glycerol-3-phosphate acyltransferase 3) axis via the TSH receptor might serve as a potential therapeutic method for obesity [42]. In this study, we investigated the fat content and it distribution in the obese patients with mild thyroid hormone deficiency and the obese patients with normal TSH. The results showed no difference in fat content and distribution in these 2 groups. It may due to the fact that the action of the slightly increased TSH levels in adipocytes is mild. However, the levels of CRP were significantly higher in obesity with mild increased TSH group. Additionally, serum TSH was positively correlated with CRP and UA in all subjects. The results may indicate that the compensatory thyroid insufficiency may be accompanied with a low-grade inflammatory state.

Previous study showed that vitamin D deficiency is common and has been related to several non-bone related outcomes that includes insulin resistance and type 2 diabetes [43]. The results of this study showed that the levels of 25-hydroxyvitamin D were lower in the obesity with mild increased TSH group than obesity with normal TSH group with statistical difference. This indicated that the mild hypothyroidism may exhibit decreased 25-hydroxyvitamin D.

Peripheral FT4 concentrations regulate TSH secretion by negative feedback inhibition [44]. Therefore, TSH values alone may not be a true measure of hypopituitarism. The TSHI and sTSHI were calculated to estimate the pituitary-thyrotroph function. The results showed that TSHI and STSHI were significantly higher in obesity with mild increased TSH. That may mean central thyroid hormone signaling is impaired in obesity. Additionally, a significantly lower GD level was observed in obesity with mild increased TSH group when compared to obesity with normal TSH group. The reduced GT may afford proof that exist impaired secretory capacity at the site of the thyroid in obesity. Therefore, we can infer that a multifactorial mechanism may act in common leading to increased TSH concentrations in obesity. The obese patients complicated by mild thyroid hormone deficiency had higher insulin levels, more serious lipid metabolism, and low-grade inflammation. A multifactorial mechanism leads to increased TSH concentrations in obesity. The need to infer the 
mild increased TSH for improving thyroid function may not only improve the glucose and lipid metabolism but also reduce the low-grade inflammation in obesity.

\section{Acknowledgements}

The authors gratefully acknowledge the financial from the Shanghai Shenkang Prevention Prog of Disease (No. SHDC12012303) and Chinese Medical Association Fund (No. 12020550355).

\section{Conflict of Interest}

$\nabla$

The authors declare no conflict of interest.

\section{References}

1 Helfand M. Screening for subclinical thyroid dysfunction in nonpregnant adults: a summary of the evidence for the U.S. Preventive Services Task Force. Ann Intern Med 2004; 140: 128-141

2 Hoermann R, Midgley JE, Larisch R, Dietrich JW. Integration of Peripheral and Glandular Regulation of Triiodothyronine Production by Thyrotropin in Untreated and Thyroxine-Treated Subjects. Horm Metab Res 2015; 47: 674-680

3 Spencer CA, Schwarzbein D, Guttler RB, LoPresti JS, Nicoloff JT. Thyrotropin (TSH)-releasing hormone stimulation test responses employing third and fourth generation TSH assays. J Clin Endocrinol Metab 1993; 76: 494-498

4 Vanderpump MP, Tunbridge WM, French JM, Appleton D, Bates D, Clark F, Grimley Evans J, Hasan DM, Rodgers H, Tunbridge F, Young ET. The incidence of thyroid disorders in the community: a twenty-year follow-up of the Whickham Survey. Clin Endocrinol 1995; 43: 55-68

5 de Moura Souza A, Sichieri R. Association between serum TSH concentration within the normal range and adiposity. European journal of endocrinology/Eur Fed Endocr Soc 2011; 165: 11-15

6 Verma A, Jayaraman M, Kumar HK, Modi KD. Hypothyroidism and obesity. Cause or effect? Saudi Med J 2008; 29: 1135-1138

7 Karthick N, Dillara K, Poornima KN, Subhasini AS. Dyslipidaemic changes in women with subclinical hypothyroidism. J Clin Diagnos Res 2013; 7: 2122-2125

8 Rondeau G, Rutamucero $N$, Messier V, Burlacu L, Prud'homme D, Mircescu $H$, Rabasa-Lhoret $R$. Reference range thyroid-stimulating hormone is associated with physical activity energy expenditure in overweight and obese postmenopausal women: a Montreal-Ottawa New Emerging Team Study. Metab Clin Exp 2010; 59: 1597-1602

9 Waring AC, Rodondi N, Harrison S, Kanaya AM, Simonsick EM, Miljkovic I, Satterfield S, Newman AB, Bauer DC. Thyroid function and prevalent and incident metabolic syndrome in older adults: the Health, Ageing and Body Composition Study. Clin Endocrinol 2012; 76: 911-918

10 Kilicaslan B, Tigen MK, Tekin AS, Ciftci H. Cardiac changes with subclinical hypothyroidism in obese women. Turk Kardiyoloji Dernegi Arsivi 2013; 41: 471-477

11 Tanase DM, Ionescu SD, Ouatu A, Ambarus V, Arsenescu-Georgescu C. Risk assessment in the development of atrial fibrillation at patients with associate thyroid dysfunctions. Rev Medico-Chirurg Soc Medici Natural Din Iasi 2013; 117: 623-629

12 Ruiz-Tovar J, Boix E, Galindo I, Zubiaga L, Diez M, Arroyo A, Calpena R. Evolution of subclinical hypothyroidism and its relation with glucose and triglycerides levels in morbidly obese patients after undergoing sleeve gastrectomy as bariatric procedure. Obes Surg 2014; 24 : 791-795

13 Zhang J, Jiang R, Li L, Li P, Li X, Wang Z, Li L, Teng W. Serum thyrotropin is positively correlated with the metabolic syndrome components of obesity and dyslipidemia in chinese adolescents. Int J Endocrinol 2014289503

14 Jostel A, Ryder WD, Shalet SM. The use of thyroid function tests in the diagnosis of hypopituitarism: definition and evaluation of the TSH Index. Clin Endocrinol 2009; 71: 529-534

15 Dietrich JW, Stachon A, Antic B, Klein HH, Hering S. The AQUA-FONTIS study: protocol of a multidisciplinary, cross-sectional and prospective longitudinal study for developing standardized diagnostics and classification of non-thyroidal illness syndrome. BMC Endocr Disord 2008; 8: 13
16 Onat A, Hergenc G, Yuksel H, Can G, Ayhan E, Kaya Z, Dursunoglu D. Neck circumference as a measure of central obesity: associations with metabolic syndrome and obstructive sleep apnea syndrome beyond waist circumference. Clin Nutr (Edinburgh, Scotland) 2009; 28: 46-51

17 Genuth S, Alberti KG, Bennett P, Buse J, Defronzo R, Kahn R, Kitzmiller J, Knowler WC, Lebovitz H, Lernmark A, Nathan D, Palmer J, Rizza R, Saudek C, Shaw J, Steffes M, Stern M, Tuomilehto J, Zimmet P. Followup report on the diagnosis of diabetes mellitus. Diabetes Care 2003; 26: $3160-3167$

18 Back GiulianoIde C,Caramelli B, Pellanda L,Duncan B,MattosS, Fonseca FH. I guidelines of prevention of atherosclerosis in childhood and adolescence. Arquiv Brasil Cardiol 2005; 85 (Suppl 6): 4-36

19 Ryu KA, Kang HH, Kim SY, Yoo MK, Kim JS, Lee CH, Wie GA. Comparison of nutrient intake and diet quality between hyperuricemia subjects and controls in Korea. Clin Nutr Res 2014; 3: 56-63

20 Biondi B, Cooper DS. The clinical significance of subclinical thyroid dysfunction. Endocr Rev 2008; 29: 76-131

21 Januszek-Trzciakowska A, Malecka-Tendera E. Subclinical hypothyroidism in obese children. Postepy Higieny Med Doswiad (Online) 2013; 67: 770-774

22 Javed Z, Sathyapalan $T$. Levothyroxine treatment of mild subclinica hypothyroidism: a review of potential risks and benefits. Therap Adv Endocrinol Metab 2016; 7: 12-23

23 Demidova T, Galieva OR. The role of thyroid hypofunction in development of metabolic syndrome. Terapevti Arkhiv 2009; 81: 69-73

24 Lai Y, Wang J, Jiang F, Wang B, Chen Y, Li M, Liu H, Li C, Xue H, Li N, Yu J, Shi L, Bai X, Hou X, Zhu L, Lu L, Wang S, Xing $Q$ Teng X, Teng $W$, Shan $Z$. The relationship between serum thyrotropin and components of metabolic syndrome. Endocr J 2011; 58: 23-30

25 Kadiyala $R$, Peter R, Okosieme OE. Thyroid dysfunction in patients with diabetes: clinical implications and screening strategies. Int J Clin Pract 2010; 64: 1130-1139

26 Gao CX, Yang B, Guo Q Wei LH, Tian LM. High thyroid-stimulating hormone level is associated with the risk of developing atherosclerosis in subclinical hypothyroidism. Horm Metab Res 2015; 47: 220-224

27 Betry C, Challan-Belval MA, Bernard A, Charrie A, Drai J, Laville M, Thivolet C, Disse E. Increased TSH in obesity: Evidence for a BMI-independent association with leptin. Diabetes Metab 2015; 41: 248-251

28 Asvold BO, Bjoro T, Vatten LJ. Association of serum TSH with high body mass differs between smokers and never-smokers. J Clin Endocrinol Metab 2009; 94: 5023-5027

29 Gowachirapant S, Melse-Boonstra A, Winichagoon P, Zimmermann MB. Overweight increases risk of first trimester hypothyroxinaemia in iodine-deficient pregnant women. Mater Child Nutr 2014; 10: 61-71

30 Aljohani NJ, Al-Daghri NM, Al-Attas OS, Alokail MS, Alkhrafy KM, Al-Othman A, YakoutS, Alkabba AF, Al-Ghamdi AS, Almalki M, Buhary BM, Sabico $S$. Differences and associations of metabolic and vitamin D status among patients with and without sub-clinical hypothyroid dysfunction. BMC Endocr Disord 2013; 13: 31

31 Emokpae MA, Adeleke SI, Uwumarongie HO. Subclinical hypothyroidism in childhood obesity and its correlation with lipoproteins. African J Med Med Sci 2011; 40: 361-365

32 Chikunguwo S, Brethauer S, Nirujogi V, Pitt T, Udomsawaengsup S, Chand $B$, Schauer $P$. Influence of obesity and surgical weight loss on thyroid hormone levels. Surg Obes Rel Dis 2007; 3: 631-635 discussion 635-636

33 Mamtani M, Kulkarni H, Dyer TD, Almasy L, Mahaney MC, Duggirala $R$, Comuzzie AG, Samollow PB, Blangero J, Curran JE. Increased waist circumference is independently associated with hypothyroidism in Mexican Americans: replicative evidence from two large, populationbased studies. BMC Endocr Disord 2014; 14: 46

34 Liu D, Jiang F, Shan Z, Wang B, Wang J, Lai Y, Chen Y, Li M, Liu H, Li C, Xue H, Li N, Yu J, Shi L, Bai X, Hou X, Zhu L, Lu L, Wang S, Xing Q, Teng W. A cross-sectional survey of relationship between serum TSH level and blood pressure. J Human Hypertens 2010; 24: 134-138

35 Sert A, Pirgon O, Aypar E, Yilmaz H, Odabas D. Subclinical hypothyroidism as a risk factor for the development of cardiovascular disease in obese adolescents with nonalcoholic fatty liver disease. Pediatr Cardiol 2013; 34: 1166-1174

36 Duntas LH. Thyroid disease and lipids. Thyroid 2002; 12: 287-293

37 Lee YK, Kim JE, Oh HJ, Park KS, Kim SK, Park SW, Kim MJ, Cho YW. Serum TSH level in healthy Koreans and the association of TSH with serum lipid concentration and metabolic syndrome. Korean J Intern Med 2011; 26: 432-439

38 Takashima N, Niwa Y, Mannami T, Tomoike H, Iwai N. Characterization of subclinical thyroid dysfunction from cardiovascular and metabolic viewpoints: the Suita study. Circul J 2007; 71: 191-195 
39 Rotondi M, Leporati P, Rizza MI, Clerici A, Groppelli G, Pallavicini C, La Manna A, Fonte R, Magri F, Biondi B, Chiovato L. Raised serum TSH in morbid-obese and non-obese patients: effect on the circulating lipid profile. Endocrine 2014; 45: 92-97

40 Bastemir M, Akin F, Alkis E, Kaptanoglu B. Obesity is associated with increased serum TSH level, independent of thyroid function. Swiss Med Week 2007; 137: 431-434

41 Bianco AC, McAninch EA. The role of thyroid hormone and brown adipose tissue in energy homoeostasis. Lancet Diabetes Endocrinol 2013; 1: 250-258
42 Ma S, Jing F, Xu C, Zhou L, Song Y, Yu C, Jiang D, Gao L, Li Y, Guan Q, Zhao J. Thyrotropin and obesity: increased adipose triglyceride content through glycerol-3-phosphate acyltransferase 3. Sci Rep 2015; 5: 7633

43 Garanty-Bogacka B, Syrenicz M, Goral J, Krupa B, Syrenicz J, Walczak $M$, Syrenicz A. Serum 25-hydroxyvitamin D (25-OH-D) in obese adolescents. Endokrynol Polska 2011; 62: 506-511

44 Ercan-Fang S, Schwartz HL, Mariash CN, Oppenheimer JH. Quantitative assessment of pituitary resistance to thyroid hormone from plots of the logarithm of thyrotropin versus serum free thyroxine index. J Clin Endocrinol Metab 2000; 85: 2299-2303 